\title{
Uma abordagem de avaliação de processos baseados no mundo dos custos para processos no mundo dos ganhos em instituições de ensino superior
}

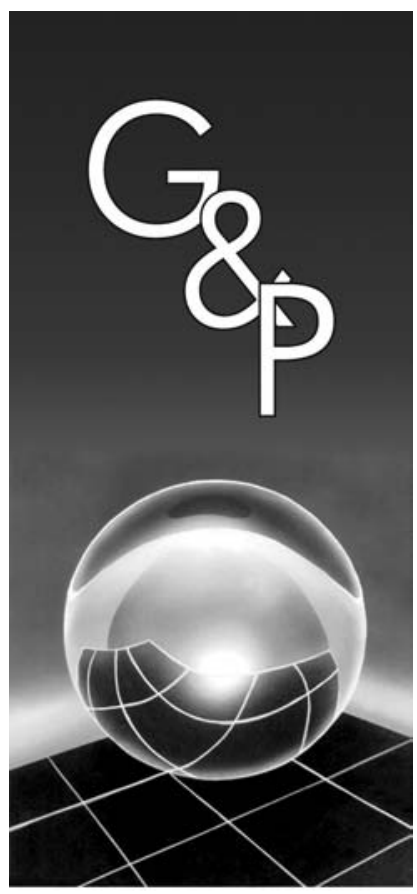

Daniel Pacheco Lacerda

Luis Henrique Rodrigues

Alexandre Costa da Silva

Resumo

O presente artigo detalha o processo específico de elaboração de preços à luz dos princípios da Contabilidade de Custos para uma organização de ensino superior. $O$ trabalho propõe uma revisão desse processo, tendo como pano de fundo os conceitos da Teoria das Restrições, no que tange a seu Processo de Raciocínio, e as premissas de custos adotadas na chamada Contabilidade dos Ganhos. Assim, o processo de elaboração do preço é avaliado sistemicamente e um redesenho desse processo alinhado à Contabilidade dos Ganhos é proposto.

Palavras-chave: Contabilidade dos Ganhos. Contabilidade de Custos. Teoria das Restrições. Engenharia de Processos de Negócios.

\section{Introdução}

Segundo Goldratt (1991), a contabilidade de custos teve um importante papel no desenvolvimento das organizações no início do século XX. Entretanto, com o desenvolvimento tecnológico, os pressupostos que sustentavam a contabilidade de custos já não são mais válidos. Nessa linha, Corbett (1997) ressalta que a contabilidade de custos não garante por si só o sucesso mas é uma condição necessária; avalia também que a contabilidade de custos vem ignorando as mudanças ocorridas no ambiente competitivo.

Concernente a isto, Goldratt (1991) argumenta que, apesar da comunidade financeira admitir que a Contabilidade de Custos não seja mais aplicável, ainda se procura considerar esta solução. Nessa busca, se esquece o principal: "ser capaz de julgar o impacto de qualquer decisão local sobre o resultado final" (GOLDRATT, p. 34, 1991).

Assim sendo, diversos autores (GOLDRATT, 1991; CSILLAG, 1991; GUERREIRO, 1996; CORBETT, 1997; DUGDALE; JONES, 1997; GRAVES; GURD, 1998; DRAMAN; LOCKAMY III; COX III, 2002) pregam a existência de dois mundos: o Mundo dos Custos e o Mundo dos Ganhos. O Mundo dos Custos congrega os pressupostos da Contabilidade de Custos, já o Mundo dos Ganhos é a alternativa apresentada pela Teoria das Restrições. Os sistemas organizacionais são, em geral, influenciados pela lógica contábil que sustenta os sistemas de custo, os quais deveriam evoluir conforme os sistemas de gestão, sob pena de fornecerem informações que levem a decisões incorretas (BORNIA, 2002).

A gestão universitária caracteriza-se pelo desenvolvimento de ensino, pesquisa e extensão. Para esse desenvolvimento, realizam-se atividades comuns a outras organizações e atividades específicas como: processos de matrícula, desenvolvimento de projetos de pesquisa, cursos de extensão, processo vestibular, entre outros.

Os processos e atividades comuns a outras organizações e os específicos da gestão universitária são influenciados por indicadores e medidores financeiros e não-financeiros, seja na fase de planejamento, de desenvolvimento ou de avaliação. No que tange aos indicadores e medidores 
financeiros, existe a influência da lógica do Mundo dos Custos ou da lógica do Mundo dos Ganhos.

Assim sendo, o presente trabalho propõe o redesenho dos processos sustentados pelos pressupostos do Mundo dos Custos, para um conjunto de processos sustentados pela lógica do Mundo dos Ganhos nas organizações. Esses processos serão redesenhados a partir da análise de uma Instituição de Ensino Superior (IES), caracterizando, por consequência, a importância do conceito de gestão universitária. Como base teórica de análise utilizou-se o Processo de Raciocínio da Teoria das Restrições, o qual auxiliou na construção da abordagem proposta nesse trabalho.

\section{Referencial teórico}

A seguir são apresentados os três pilares teóricos desse trabalho: i) o Mundo dos Custos e o Mundo dos Ganhos; ii) o Processo de Raciocínio da Teoria das Restrições; e iii) conceituações referentes ao Mapeamento de Processos. Não se pretende esgotar o assunto, mas apresentar pontos que contribuem para o entendimento do trabalho.

\subsection{Breves considerações teóricas sobre o mundo dos custos e o mundo dos ganhos}

O conflito entre o Mundo dos Custos e o Mundo dos Ganhos ocorre na forma como cada um desses paradigmas vê a organização. O pressuposto principal do Mundo dos Custos está em controlar o custo, enquanto o principal pressuposto do Mundo dos Ganhos está em proteger o ganho (GOLDRATT, 1991; GOLDRATT, 2004b).

Em relação ao Mundo dos Custos, cada elemento (elo) da organização (departamento, pessoas, funções) consome recursos financeiros, materiais e tempo. $\mathrm{O}$ custo de toda a organização é o somatório dos custos de cada um dos elementos da organização. Este é o mundo das variáveis independentes (GOLDRATT, 1991).

Através dessa lógica, no Mundo dos Custos o ótimo global é alcançado por meio dos ótimos locais. Assim, cada produto que a empresa comercializa deve remunerar seu próprio custo e contribuir para o alívio dos custos dos demais elementos da empresa. Por esse raciocínio, o preço de um produto é formado pelo seu próprio custo, agregado a um determinado percentual dos demais custos da organização e a uma margem de lucro do produto tal que remunere a organização e seus acionistas pelo desenvolvimento de suas atividades.

Isso se expressa pelos métodos de alocação dos custos fixos (diretos e indiretos), através de rateios (critérios para distribuição dos custos). Portanto, sabe-se a eficiência de um produto bem como a eficiência da organização através da redução dos custos dos produtos. Essa redução pode ocorrer através da diminuição dos custos diretos ou indiretos, por exemplo.
O Mundo dos Custos posiciona em grau de importância as seguintes medidas: a) Despesas Operacionais; b) Ganho; c) Inventário (estoques) (GOLDRATT, 1991; GOLDRATT, 1992; CSILLAG, 1991; CORBETT, 1997; PLANTULLO, 1994; MARQUES; CIA, 1998 ) como balizadores para a tomada de decisões nas organizações.

$\mathrm{Na}$ lógica do Mundo dos Custos, as informações para a tomada de decisões são o lucro e o custo dos produtos. Para que essa informação esteja o mais próximo possível da realidade existem diversos métodos de custeio que buscam os critérios mais adequados para a alocação dos custos aos produtos, para que, assim, se verifique com o maior nível de exatidão o real custo de um produto e, por consequência, o real lucro que proporciona. Assim, é possível que alguns produtos estejam reduzindo a lucratividade da organização, uma vez que geram prejuízos. Esse fenômeno ocorre quando o preço pelo qual o produto é vendido é inferior aos seus custos totais (diretos e indiretos). Assim, em tese, quanto maior for a venda desse produto, maior será o prejuízo da organização. Nas organizações sem fins lucrativos, os produtos devem deixar margens de lucro que garantam a viabilidade econômico-financeira e, por consequência, a sustentabilidade de suas operações. Contudo, o possível resultado positivo gerado deve ser reinvestido integralmente no negócio. Essas instituições não comportam o procedimento de distribuição de lucros e dividendos. Entretanto, mesmo nas organizações sem fins lucrativos podem ser aplicadas as lógicas do Mundo dos Custos ou dos Ganhos.

Segundo Goldratt (1991, p. 48): "O Mundo dos Ganhos é o mundo das variáveis dependentes". Isso significa que o ótimo da organização não ocorre pelo somatório dos ótimos locais. Pela lógica do Mundo dos Ganhos, a melhoria da organização é realizada por meio de melhorias na restrição. Assim sendo, as ações de melhoria organizacional deveriam focar-se em poucos pontos (restrições), o que permitiria um resultado para a empresa como um todo. Dentre as diversas ações para a melhoria nas restrições podem-se citar, ilustrativamente: i) definição de um melhor mix de produção em função da restrição; ii) redução dos tempos de produção/preparação especificamente na operação restritiva; iii) ampliação da capacidade produtiva especificamente no recurso restritivo; iv) cálculo do retorno de investimento considerando o recurso restritivo; v) identificação e priorização dos produtos com maior ganho em relação a sua ocupação da restrição; e vi) políticas de gestão de riscos e planos de contingência específicos para a restrição.

Assim o Mundo dos Ganhos se coloca em contraposição a lógica do Mundo dos Custos. Nesta nova lógica, o fator determinante é a restrição, pois ela determina a lucratividade da empresa como um todo. "No Mundo dos Ganhos, as restrições são a classificação essencial, substituindo a função que os produtos exerciam no Mundo dos Custos" 
(GOLDRATT, p. 51, 1991). Por consequência, nem sempre uma melhoria local resulta numa melhoria global.

No raciocínio do Mundo dos Ganhos não existem o lucro dos produtos, mas sim o lucro da empresa. O Mundo dos Ganhos trabalha com o conceito de Ganho. Ganho é o resultado do preço de venda menos os custos totalmente variáveis. Os demais custos são considerados como Despesa Operacional ou Inventário (GOLDRATT, 1991; CSILLAG, 1991; GARDNER; BLACKSTONE; JOHN, 1991; PLANTULLO, 1994; DUGDALE; JONES, 1997; GRAVES; GURD, 1998; CORBETT, 1997).

Sendo a restrição o fator determinante para o resultado da organização, o que define as decisões, no Mundo dos Ganhos é o Ganho em relação à utilização da restrição. As Despesas Operacionais da organização devem ser cobertas pelo somatório dos Ganhos obtidos pelos produtos. O Mundo dos Ganhos coloca em grau de importância as seguintes medidas: a) Ganho; b) Inventários; c) Despesa Operacional (GOLDRATT, 1991; CSILLAG, 1991; CORBETT, 1997; PLANTULLO, 1994; GUERREIRO, 1996; MARQUES; CIA, 1998) como balizadores para a tomada de decisões nas organizações. Uma vez que a organização está se aprimorando continuamente, a Despesa Operacional e os Inventários são uma alternativa limitada a esse processo de melhoria.

As críticas feitas pelos defensores dos métodos de custeio alinhados ao Mundo dos Custos em relação ao Mundo dos Ganhos estão centradas em quatro pontos: no horizonte de tempo para a tomada de decisões; na não utilização das informações para necessidades fiscais; no controle dos custos fixos e na alegação de que a Teoria das Restrições não traz elementos novos à Contabilidade de Custos.

Por um lado, em relação ao horizonte de tempo, as críticas realizadas informam que as decisões baseadas no Mundo dos Ganhos são eminentemente de curto prazo pois, no longo prazo, todos os custos (fixos diretos e indiretos) devem ser cobertos. Nesse sentido, comercializar produtos que não cobrem os custos totais (variáveis e fixos) pode comprometer a viabilidade da empresa. Por outro lado, argumenta-se que não vender, em função da cobertura dos custos fixos totais, pode comprometer a viabilidade da empresa no curto prazo (CORBETT, 1997; MOTTA, 2000). O segundo ponto está vinculado à impossibilidade de utilizar as informações geradas para decisões, de acordo com a Teoria das Restrições, de fins fiscais. Isso decorre do fato de que, em termos fiscais, todos os custos devem ser agregados no cálculo do custo unitário do produto, principalmente para valoração dos estoques.

O terceiro ponto, por sua vez, está associado à crítica de que, se a empresa mantiver-se focada prioritariamente no Ganho, poderá haver um descontrole dos custos fixos. Esse descontrole, sendo recorrente, poderia comprometer a viabilidade econômico-financeira da firma. Por fim, o quarto elemento de crítica informa que a Teoria das Restrições se associa ao Princípio do Custeio Variável e ao fator limitante de produção, portanto, esses princípios eram conhecidos. Bornia (2002) afirma que o Ganho do produto, basicamente, é a margem de contribuição (utilizada no custeio variável) menos a mão-de-obra direta. Bornia (2002) vai além, afirmando que o conceito de ganho em relação à restrição era prática comum quando da aplicação correta do custeio variável. A técnica de margem de contribuição sob o fator limitante já era conhecida e aplicada antes mesmo da constituição da Teoria das Restrições (BORNIA, 2002).

Dessas críticas apresentadas duas, basicamente, poderiam estar associadas a esse trabalho. A crítica em relação ao horizonte de tempo, no sentido de que se forem comercializado todos os cursos em que apenas os custos variáveis estão cobertos no longo prazo a IES não é sustentável. Essa visão se sustenta no fato de que não haverá recursos para manter a IES atualizada em termos de infra-estrutura, por exemplo. Contudo, esse trabalho não é excludente. Isso significa que, em havendo condições de obtenção de um maior valor por produto da IES não é necessário que se comercialize apenas acima dos custos variáveis.

A segunda crítica que pode ser relacionada ao trabalho está vinculada ao descontrole dos custos fixos. Assim, a não incorporação dos custos fixos (diretos e indiretos) aos produtos poderia levar a uma situação perdulária e ao descontrole dos custos. Isso decorreria do fato de que, ao estabelecer a precificação dos produtos, esses custos não iriam compor seu cálculo. Nesse sentido não há uma relação direta, pois o controle de custos deve ser uma constante nas organizações. Contudo, isso não implica em que os mesmos sejam agregados aos produtos. Além disso, a incorporação desses custos pode penalizar a organização com a falta de recursos, no curto prazo, para sua viabilidade econômico-financeira.

\subsection{O processo de raciocínio da teoria das restrições}

Para Antunes Jr. et al. (2004) o Processo de Raciocínio da Teoria das Restrições pode ser considerado um método de identificação, análise e solução de problemas. $\mathrm{O}$ Processo de Raciocínio é um método que procura facilitar a liberação, focalização e crítica da intuição e se constitui, portanto, em um conjunto de ferramentas que procura facilitar a verbalização do bom senso (GOLDRATT, 1990; McMULLEN, 1998; SCHEINKOPF, 1999).

Para Cox e Spencer (2002), o Processo de Raciocínio é um conjunto de ferramentas que podem ser utilizadas individualmente ou estar ligadas logicamente, permitindo a identificação de problemas centrais, determinação de soluções do tipo ganha-ganha e superação dos obstáculos possíveis para implementação da solução. O Processo de Raciocínio utiliza-se do método científico e busca responder três perguntas: O quê mudar? Para o quê mudar? 
e Como provocar a mudança? A lógica do Processo de Raciocínio baseia-se em relações de efeito-causa-efeito e na visão crítica da realidade, a qual procura saber por que as coisas acontecem e não como elas acontecem (ALVAREZ, 1995).

Conforme Smith (2000) e Cox e Spencer (2002), a Teoria das Restrições possui cinco ferramentas que visam responder essas três perguntas fundamentais representadas no Quadro 1. As ferramentas empregadas sustentam-se em dois pontos centrais: a visão crítica da realidade, e a análise efeito-causa-efeito (ALVAREZ, 1995). Para os fins desse trabalho apresenta-se a Árvore da Realidade Atual e a Evaporação das Nuvens.

O objetivo principal da Árvore da Realidade Atual é a definição dos problemas centrais encontrados em um sistema específico (ANTUNES Jr. et al., 2004). De acordo com Kingman (1996), a construção da Árvore da Realidade Atual deve ser realizada em grupos inter-funcionais. Kingman (1996) ainda salienta que essa ferramenta proporciona uma efetiva comunicação dos principais problemas da empresa e um entendimento comum desses problemas.

Para Klein e DeBruine (1995) e Cox e Spencer (2002), a Árvore da Realidade Atual construída completamente fornece meios para: i) identificar o impacto de políticas, procedimentos e ações na organização; ii) comunicar clara e concisamente a causalidade dessas políticas, procedimentos e ações; iii) identificar claramente o problema central em uma situação; e iv) permite a criação de um clima favorável de relação ante os problemas, colocando toda a massa crítica contra o problema central.

A Evaporação das Nuvens procura verbalizar pressupostos não verbalizados que causam os problemas centrais. Em geral, esses problemas centrais têm origem em um conflito de posições (ANTUNES Jr. et al., 2004). Alvarez (1995) complementa que, para resolver esses problemas centrais (conflitos), em um número expressivo de casos se utilizam soluções de compromisso.

As soluções de compromisso são decisões tomadas privilegiando uma posição conflitante em relação a outra.

Quadro 1. Cinco ferramentas do processo de raciocínio.

\begin{tabular}{|ll|}
\hline \multicolumn{1}{|c|}{ Pergunta central } & \multicolumn{1}{c|}{ Ferramenta } \\
O quê mudar? & Árvore da Realidade Atual \\
Para o quê mudar? & (Current Reality Tree - CRT) \\
& $\begin{array}{l}\text { Evaporação das Nuvens } \\
\text { (Evaporating Clouds) }\end{array}$ \\
& Árvore da Realidade Futura \\
& (Future Reality Tree - FRT) \\
Como provocar a mudança? & $\begin{array}{l}\text { Árvore dos Pré-requisitos } \\
\text { (Prerequisite Tree }-P R T)\end{array}$ \\
& Árvore de Transição \\
& (Transition Tree - TT)
\end{tabular}

Fonte: Adaptado de Cox e Spencer (2002).
São soluções conciliatórias que, em geral, já haviam sido implementadas em tentativa de resolver o problema (GOLDRATT, 1991). Na atividade de gestão, há situações de trade-off. As trade-offs são situações nas quais o gestor deve fazer uma opção em detrimento de outra. Nessas situações, segundo a Teoria das Restrições, há sempre uma solução simples e criativa que rompe com os pressupostos estabelecidos em relação ao problema central (GOLDRATT, 2004a; ALVAREZ, 1995; KLEIN; DEBRUINE, 1995; NOREEN; SMITH; MACKEY, 1996; COX; SPENCER, 2002; ANTUNES Jr. et al., 2004). A Figura 5 explicita uma situação em que há dois caminhos distintos para um mesmo objetivo comum. Assim sendo, há uma trade-off, ou seja, uma situação onde o gestor pode decidir por um caminho ou outro. A Evaporação das Nuvens, ilustrada na Figura 5, contribui para explicitar os pressupostos que sustentam o aparente conflito. Dessa maneira se busca desenvolver uma solução que elimine algum dos pressupostos e, por consequência, o conflito existente.

\subsection{Mapeamento de processos}

Segundo Davenportt (1994), processos são ordenações das atividades do trabalho no tempo e no espaço, com início e fim, entradas e saídas claramente identificadas. Em outras palavras, é uma estrutura direcionada para a ação. Johansson et al. (1995) definem os processos como um conjunto de atividades interligadas que recebem insumos e os transformam para criar valor para a organização.

Rummler e Brache (1994) e Slack et al. (1999) expandem o conceito de processos, uma vez que os visualizam para a produção de bens e de serviços. Os processos organizacionais estão ligados a atividades necessárias à existência da empresa. De certa forma, pode-se dizer que uma empresa é tão eficiente quanto os seus processos o são (JOHANSSON et al., 1995; RUMMLER; BRACHE, 1994). Reforçando esta afirmação, Harrington (1993) relata que esses processos compreendem as atividades fundamentais da administração de uma organização.

Os processos dentro das organizações nem sempre são totalmente visíveis e conhecidos. Assim,

o mapeamento de processos seria uma ferramenta gerencial analítica de comunicação cujo objetivo seria ajudar a melhorar os processos existentes (VILLELLA, 2000, p. 50)

ou, ainda, a implantar novos processos. Essa técnica permite a redução dos custos, uma maior compreensão das atividades e um melhor desempenho da organização (HUNT, 1996). Para Pidd (1998), a modelagem de processos ajuda a aprofundar o conhecimento dos componentes essenciais que podem proporcionar melhorias efetivas.

"O mapeamento de processos inicia com os objetivos do processo, sendo o próximo passo a decomposição do objetivo em atividades e tarefas" (VILLELLA, p. 65, 2000). 
Este tipo de análise permite à organização conhecer seus processos e ter idéias com base nesta decomposição. Segundo Hunt (1996), o mapeamento de processos deve:

- expor os detalhes do processo;

- ter concisão e precisão na descrição do processo;

- focar a atenção nas interfaces do processo; e

- fornecer uma análise de processos poderosa e consistente.

\section{A abordagem metodológica}

A presente pesquisa, conforme suas características, pode ser classificada, em termos de natureza, como pesquisa aplicada, pois se trata de conhecimento com fins específicos de suplementar lacunas teórico-práticas (GIL, 2007). A abordagem adotada foi qualitativa, pois a amostra utilizada não possibilita uma avaliação mais ampla e, na verdade, o seu objetivo foi a proposição de uma abordagem teórica inicial de construção de processos à luz do Mundo dos Ganhos, com objetivos exploratórios. Em termos de procedimentos técnicos, utilizou o método de Estudo de Caso (GIL, 2007) em uma Instituição de Ensino Superior, no sentido de buscar subsídios empíricos dos processos atuais visando a construção da proposta de trabalho.

O estudo de caso é um método apropriado para investigar e entender um determinado fenômeno ou comportamento organizacional. Ele proporciona um entendimento do padrão do objeto pesquisado. Bryman (1988) considera a capacidade de produzir descrições detalhadas de fenômenos uma das principais características dos estudos qualitativos. Para isso, é importante que o objeto de estudo seja passível de observação. Yin (2001) afirma que o estudo de caso é apropriado para questões de pesquisa do tipo "como" e "por que" e nas situações em que o pesquisador estuda acontecimentos contemporâneos sobre os quais tem pouco ou nenhum controle.

Além disso, o estudo de caso pode ser utilizado para a construção de teorias. Por ser uma técnica que desenvolve uma explanação e entendimento sobre determinado fenômeno, ela possibilita a emergência de teorias. Einsenhardt (1989) apresenta a elaboração de diversas teorias a partir de estudos de casos. Para Ellram (1996), o estudo de caso pode ser utilizado para: 1) explorar um determinado assunto ou problema, entendendo-o profundamente; 2) explanar um fenômeno; 3 ) descrever um fenômeno; e 4) predizer características de um determinado fenômeno. A Figura 1 apresenta de maneira geral o método de trabalho utilizado para o desenvolvimento dessa pesquisa.

\subsection{Desenho de pesquisa}

A Figura 2 procura oferecer uma visão geral sobre o método a ser utilizado para o redesenho dos processos sob um novo olhar. Assim, o redesenho dos processos terá por sustentação teórica três eixos de revisão: i) a Teoria

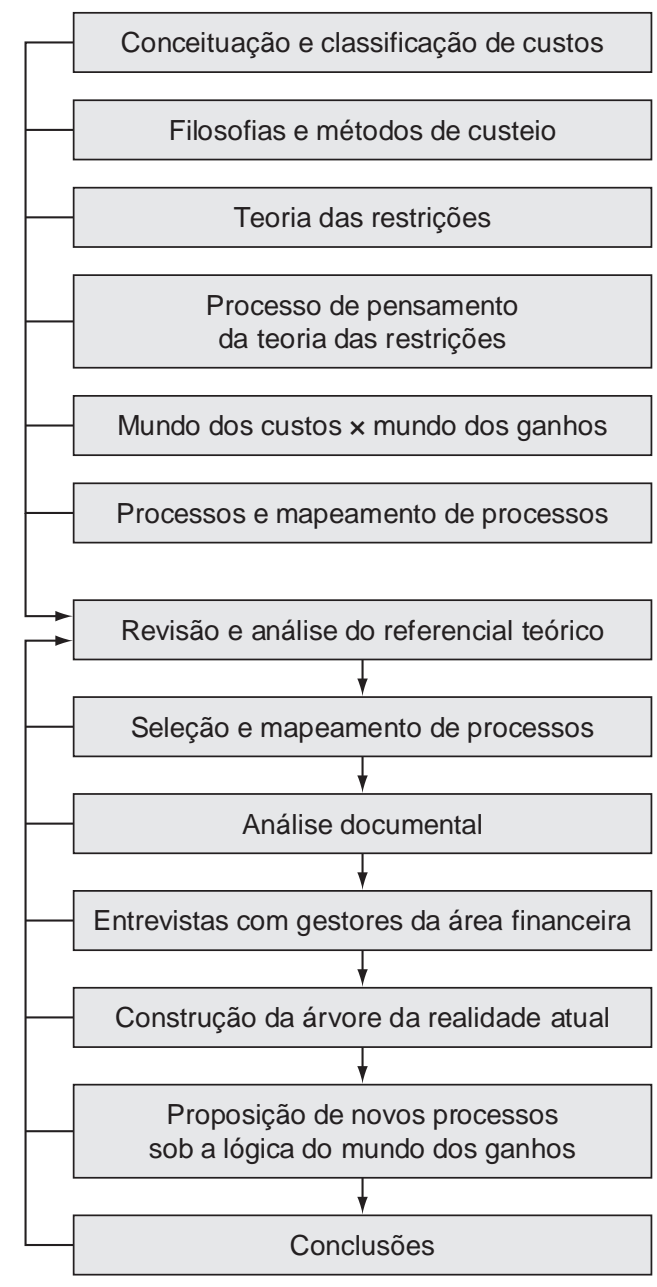

Figura 1. Estrutura de execução da pesquisa. Fonte: os autores (2009).

das Restrições; ii) Filosofias e Métodos de Custeio; e iii) Mapeamento de Processos.

A revisão das Filosofias e dos Métodos de Custeio procura contribuir para o entendimento dos custos da organização, como esses são apurados, distribuídos e avaliados. Para o entendimento da sistemática que perpassa a distribuição e a avaliação dos custos, é necessário o conhecimento das Filosofias de Custeio existentes e que fornecem os pressupostos de como a organização e seus produtos e processos são vistos. Por meio desse conhecimento, o trabalho aprofunda-se nesse tema com o intuito de analisar os métodos (instrumentos) que colocam em prática os pressupostos existentes nas Filosofias de Custeio.

De maneira concomitante, apresenta-se o Mundo dos Ganhos e seu conjunto de pressupostos determinando então o debate, a confrontação da forma de visualizar os custos e a organização entre o Mundo dos Custos e Mundo dos Ganhos, nomenclatura essa utilizada pela Teoria das Restrições para diferenciar sua perspectiva em contraposição à lógica observada em relação aos custos. 
Desempenho de pesquisa

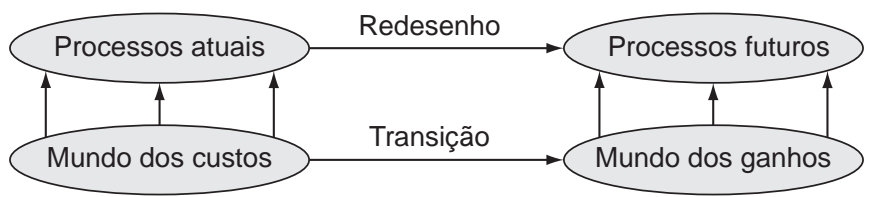

Sustentação teórica

\begin{tabular}{|c|}
\hline Teoria das restrições \\
- Processo de pensamento \\
- Indicadores \\
- Processo de focalização \\
\hline
\end{tabular}

Filosofias e métodos de custeio - Conceito e taxonomia de custos - Filosofias de custeio - Métodos de custeio
Mapeamento de processos

- Conceito de processos

- Mapeamento de processos

Figura 2. Estrutura para o Redesenho dos Processos. Fonte: os autores (2009).

Esse exercício dialético proporciona a clareza necessária para a compreensão da situação atual e para o futuro redesenho dos processos.

Nesse sentido, o Mapeamento de Processos contribui por ser o instrumental necessário à pesquisa sistemática, à descrição, à análise e ao redesenho desses processos à luz de outro conjunto de pressupostos. Procura-se dessa maneira contribuir para a transição das organizações do Mundo dos Custos para o Mundo dos Ganhos, visto que, conforme já explicitado, a literatura acumula críticas ao Mundo dos Custos e mostra as vantagens da mudança para o Mundo dos Ganhos, porém não demonstra como seriam os processos organizacionais sob essa lógica. Corbett (1997) apresenta uma proposta de tratamento para as decisões no ambiente do Mundo dos Ganhos. Entretanto, Corbett (1997) não indica como poderiam ser os processos na lógica desse ambiente. Assim, esse trabalho procura contribuir para a transição para o Mundo dos Ganhos. Talvez a falta de outros estudos sobre essa temática explique, em parte, a inércia das organizações na migração de um mundo para o outro.

\subsection{Unidade de pesquisa}

A descrição dos processos é resultado do mapeamento dos processos realizado na IES. Nesse trabalho, iniciado em junho de 2000, foram identificados 11 megaprocessos, 80 processos principais, 441 subprocessos e 1.900 atividades (transações de negócio). O mapeamento foi feito por uma equipe de 150 pessoas de diversas áreas da IES.

Realizado o corte inicial, que selecionou os megaprocessos com rotinas relevantes na área econômico-financeira, foram identificados os subprocessos que contribuiam de forma significativa para os objetivos dessa pesquisa. Nesse sentido, não foram mapeadas todas as atividades (transações de negócios), uma vez que esse nível de detalhamento pouco contribuiria para o entendimento e proposição de novas rotinas. Assim sendo, foram selecionados os seguintes processos/subprocessos:
Esses subprocessos têm envolvimento direto na área de planejamento econômico-financeiro da IES, influenciam a tomada de decisões na organização e induzem a forma de análise a ser realizada na instituição e em seus produtos e serviços.

Essa pesquisa partiu da realidade concreta - isso significa que os processos e subprocessos originais são resultado do trabalho já realizado inicialmente pela IES. Os indicadores desses processos e subprocessos foram levantados nas áreas às quais eram afetos. Contudo, uma série de entrevistas foi realizada com: i) os responsáveis pela área de planejamento econômico-financeiro; ii) gestores que tinham interface com essa área; iii) funcionários dessa área; iv) pessoas envolvidas, de alguma forma, com a comercialização desses produtos. As entrevistas procuraram garantir que os processos inicialmente mapeados permaneciam válidos.

Durante essas entrevistas foram localizados e identificados os principais efeitos indesejados inerentes a esses processos. Eles foram a base para a construção das Árvores da Realidade Atual (ARAs). Para que a ARA se estabelecesse solidamente, no seu processo de construção foram agregadas a ela outras variáveis. Após a construção das ARAs, uma das variáveis básicas que estariam sustentando a realidade e, principalmente, associar-se-iam à dicotomia Mundo dos Custos-Mundo dos Ganhos foi selecionada.

Muitas reuniões cujo fim era apresentar a ARA, explorar e identificar os requisitos, pré-requisitos e pressupostos que sustentavam a fato gerador básico selecionado foram realizadas. Tendo por base esses elementos identificados, uma das ramificações necessárias para a Evaporação das Nuvens foi construída. Valendo-se então da literatura analisada, os autores construíram a ramificação baseada nos princípios do Mundo dos Ganhos.

Com base nesses elementos, buscou-se eliminar o conflito com a complementação possível. A seguir, o processo redesenhado com a adição identificada foi proposto à luz dos conceitos apresentados pela Teoria das Restrições. Ao final, os indicadores foram revistos, em função de eles 
Quadro 2. Processos/subprocessos selecionados.

\begin{tabular}{|c|c|}
\hline 1. Verificação da Sustentabilidade & $\begin{array}{l}\text { 1.1. análise da projeção } \\
\text { econômico-financeira; } \\
\text { 1.2. precificação; }\end{array}$ \\
\hline 2. Gestão Orçamentária & $\begin{array}{l}\text { 2.1. elaboração do plano } \\
\text { de investimentos; } \\
\text { 2.2. elaboração do } \\
\text { orçamento universitário; } \\
\text { 2.3. orçamento dos } \\
\text { projetos de pesquisa; e }\end{array}$ \\
\hline 3. Contabilidade Gerencial/Custos & $\begin{array}{l}\text { 3.1. execução dos rateios } \\
\text { dos custos indiretos. }\end{array}$ \\
\hline
\end{tabular}

Fonte: os autores (2009).

relacionarem-se diretamente com a mudança estabelecida. Dessa forma, são proposições desse trabalho tanto os processos quanto os indicadores redesenhados.

\section{A abordagem proposta}

Para fins desse trabalho, apresenta-se a abordagem de um dos subprocessos mapeados. Isso é necessário para que se mostre a abordagem como um todo e se obtenha, dessa forma, maior profundidade na apresentação da proposição. O subprocesso detalhado foi o de precificação.

\subsection{A identificação do que mudar}

Nessa parte será apresentado o processo atual, seus indicadores e impactos sistêmicos observados na Árvore da Realidade Atual.

\subsubsection{O mapeamento do processo atual}

O subprocesso de precificação tem como objetivo, na IES analisada, quantificar o valor da contribuição por aluno para cobrir os custos operacionais e formar o resultado dos produtos e serviços. Assim, nesse subprocesso, tem-se por requisito as demandas mercadológicas, análise microeconômica (elasticidade e preço), estrutura instalada, investimentos necessários, custos de projetos e custos operacionais. O processo está graficamente representado na Figura 3.

Em relação aos custos, são incorporados os custos diretos e indiretos decorrentes do produto. A alocação dos custos indiretos é realizada através de rateios e do estabelecimento de uma taxa média de $25 \%$, referente ao overhead, sobre o total dos custos apurados.

A análise descrita ocorre para precificação de novos produtos. Para os produtos/serviços já oferecidos é realizada uma análise diferenciada para definição dos preços. Para os produtos/serviços em oferta não se analisa a estrutura de custos e margens dos produtos. Na realidade são feitas análises sobre algumas variáveis, como dissídio, inflação e novas definições de investimento. A utilização da capacidade instalada, investimentos adicionais em infraestrutura e obtenção do ponto de equilíbrio são considerados fatores críticos no subprocesso de precificação.

\subsubsection{Indicadores atuais}

Os indicadores utilizados pelos gestores dos produtos universitários foram desenvolvidos sob a ótica da medição local dos produtos sob sua gestão, sem a visão do impacto de seu comportamento no todo Universitário. Assim sendo, os indicadores atuais são os seguintes:

a) Custos Fixos em relação à Margem de Contribuição do Curso: Esse indicador tem por objetivo verificar o nível de comprometimento dos custos fixos do curso. Assim, apura-se, para cada unidade monetária de custo fixo envolvido, o nível de retorno das operações do curso. Por exemplo, para cada Real de Custo Fixo envolvido o produto remunera um determinado valor, o ideal é um valor superior a 0 (zero).

$$
\frac{\text { Custos Fixos }}{\text { (Receitas Líquidas - Custos Variáveis) }}
$$

Equação 1. Custos Fixos em relação à margem de contribuição do curso.

b) Resultado Operacional do Curso: Esse indicador demonstra o Resultado Operacional do curso. Cabe ressaltar que nos custos operacionais estão inclusos os rateios de custos fixos do produto, de acordo com os critérios e chaves de rateio adotados na IES.

$\underline{\text { (Receita Líquida - Custos Operacionais + Resultados Financeiros) }}$

Receitas Líquidas

Equação 2. Resultado Operacional do curso.

c) Índice de Ocupação das Turmas: O índice de ocupação das turmas procura evidenciar a eficiência da utilização dos recursos envolvidos, tendo por base o raciocínio de que aquele recurso poderia estar sendo ocupado por produtos com maior procura.

$$
\frac{\text { Vagas Ofertadas }}{\text { Vagas Ocupadas }}
$$

Equação 3. Índice de Ocupação das turmas.

\subsection{3 Árvore da realidade atual (ARA) do processo de precificação}

A ARA é uma ferramenta de base lógica usada para descrever uma realidade através de relações de causa e efeito que permitem mostrar como efeitos indesejáveis de um sistema se interligam e decorrem de poucas causas: conflitos não resolvidos e pressupostos errôneos (RODRIGUES, 2004).

A Árvore da Realidade Atual expressa na Figura 4 apresenta os pontos para a alavancagem das melhorias 


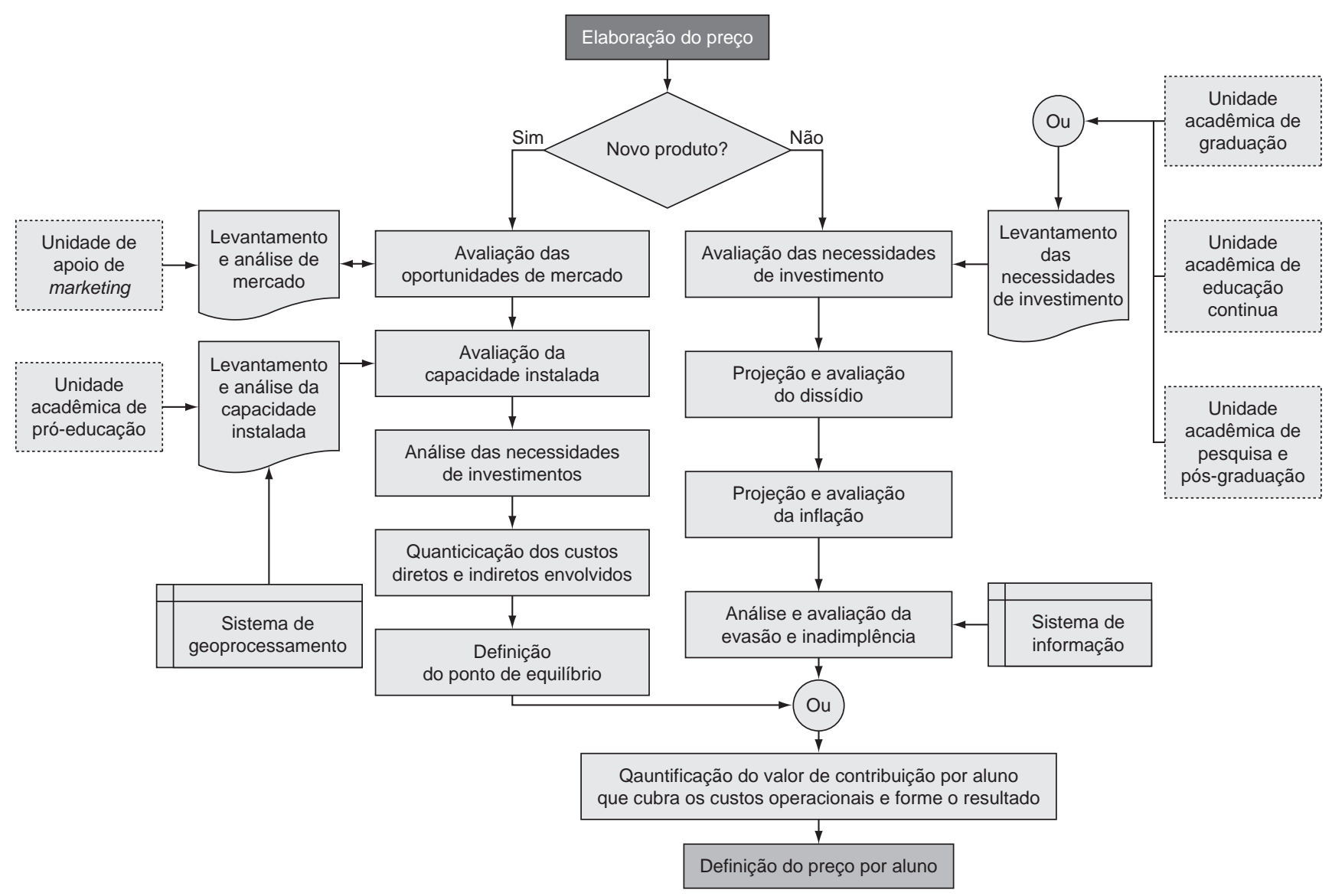

Figura 3. Fluxograma do subprocesso de precificação. Fonte: os autores.

necessárias a esse subprocesso. Nesse diagrama observa-se uma pressão em relação ao ponto de equilíbrio das atividades desenvolvidas pela IES, entretanto a obtenção desse ponto de equilíbrio é questionada em função das medidas de segurança embutidas no cálculo. De fato, há uma pressão para deslocar (aumentar) o ponto de equilíbrio em função da incorporação de custos não operacionais na composição de cálculo. Por exemplo, a proposição de um curso de extensão com oito alunos cobriria seus custos variáveis. A incorporação dos custos não operacionais (fixos indiretos e diretos), demanda 14 alunos para o mesmo resultado. Poder-se-ia supor que antes do início das aulas se tenham 11 alunos matriculados. Por um lado, a turma não estaria provendo a cobertura de todos os custos e, portanto, esse produto não deveria ser oferecido. Por outro lado, essa diferença, embora não cubra os custos totais, contribui para a redução de eventual resultado negativo. Contudo deve-se ressaltar que essa situação de oferta superior a demanda tem se configurado com frequência no ensino privado.

A leitura da ARA deve ser feita da base para o topo. As flechas são direcionadas das causas para os efeitos, estabelecendo uma lógica de relacionamentos causa-efeito desde as causas básicas até o efeito indesejado mais amplo.
Ainda com relação à simbologia na Árvore da Realidade Atual, quando um efeito resulta de causas mutuamente necessárias (sem qualquer uma delas o efeito não ocorre), grafa-se uma elipse sobre as flechas. Nesses casos de causas mutuamente necessárias basta quebrar/eliminar uma delas para eliminar a possibilidade de ocorrência dos efeitos correspondentes.

Como a sustentação da IES advém das atividades que ela desenvolve (280) e a instituição é gerida pelo princípio dos ótimos locais (260), isso gera a necessidade de que cada atividade garanta a própria sustentação (275). Desta maneira, o sistema, em suas partes, produz um conjunto de proteções, por meio de margens de segurança, que se projetam no aumento dos custos das partes. Assim sendo, os pontos de equilíbrio das atividades ficam elevados (285), resultando em uma majoração dos respectivos preços (220) e culminando no indesejável efeito de perda de alunos (200).

\subsection{Evaporação das nuvens}

A Árvore da Realidade Atual é importante para,

em vez da perda de tempo com a solução de sintomas, identificar a verdadeira causa e evitar 


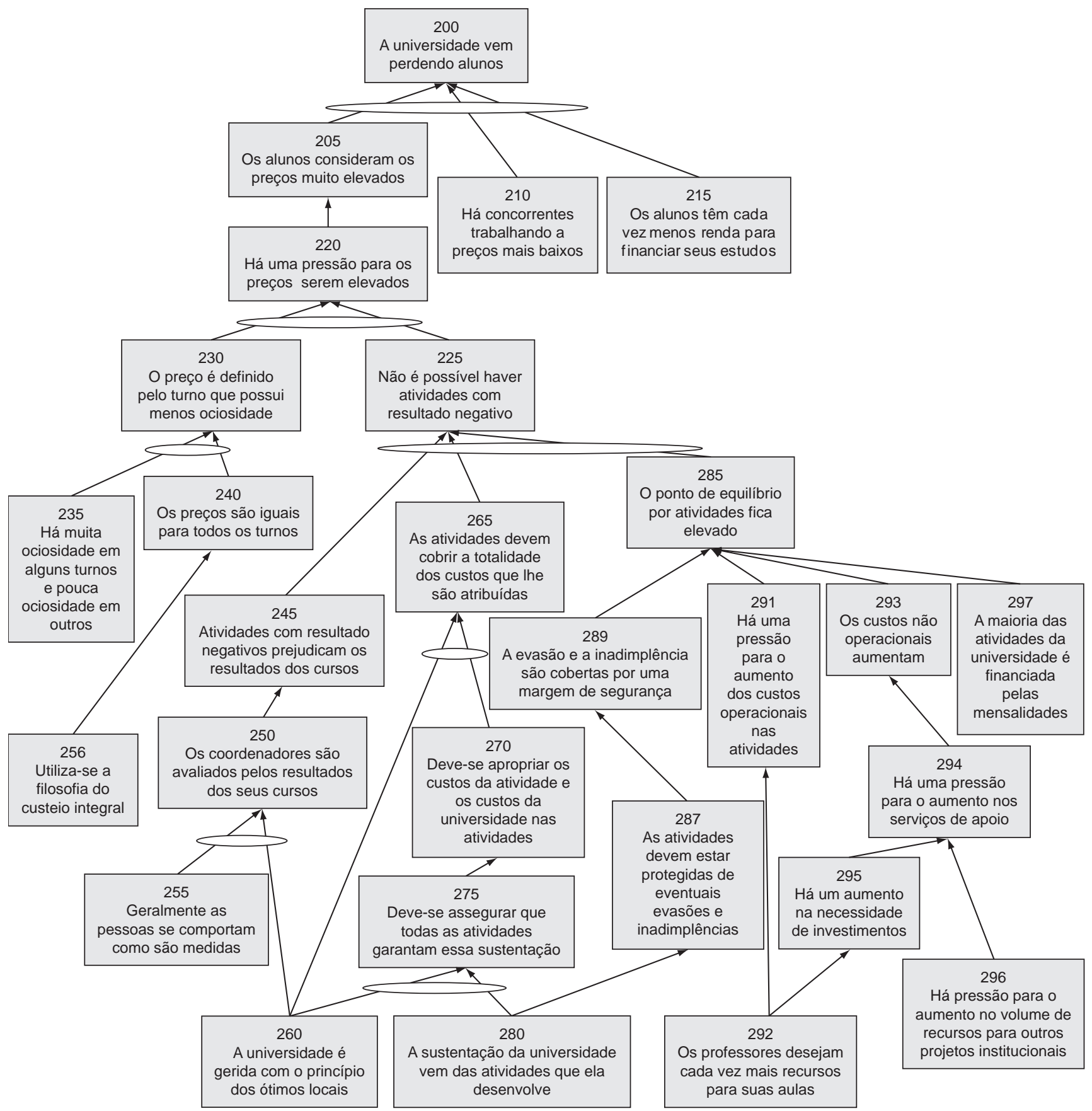

Figura 4. Árvore da Realidade Atual do subprocesso de precificação. Fonte: os autores.

que os problemas reais permaneçam" (COX; SPENCER, 2002, p. 17).

Realizando a análise da Árvore da Realidade Atual, percebe-se que a causa principal dos efeitos indesejados verificados é que "A gestão da Universidade observa o princípio dos ótimos locais". Assim, utiliza-se o Diagrama de Evaporação das Nuvens para identificar os pressupostos que sustentam a causa principal, procurando evidenciar uma ou mais injeções que possam romper esses bloqueios mentais para uma solução de nível mais alto. Uma solução que não seja de compromisso, em que cada uma das partes ceda na busca de um consenso.

Para que isso ocorra é necessário estabelecer um objetivo comum a essas duas visões gerenciais. Dessa forma é possível estabelecer que o objetivo comum seja: "Ter uma IES Sustentável e Competitiva”. Entretanto, para a consolidação desse objetivo comum duas condições se impõem: a) os departamentos precisam ser eficientes; e b) deve haver sinergia entre os departamentos. Para 
cada necessidade, a estruturação da nuvem demanda um pré-requisito correspondente, conforme a Figura 5.

Percebe-se um conflito entre os pré-requisitos "Avaliar os departamentos localmente" e "Avaliar os departamentos globalmente". Esse conflito sustenta-se nos pressupostos destacados nas elipses do diagrama. Pela lógica, para atender aos pressupostos é necessário avaliar os departamentos localmente, pois controlando-se cada deles de modo a funcionarem melhor o todo irá na mesma direção, podendo as ações corretivas, ainda, influenciar os que não estão contribuindo.

Para romper com essa visão é apresentada na Figura 5 a criação de indicadores processuais cujo fim é motivar as partes a agirem globalmente. Nesta lógica, todos os departamentos trabalham para o todo. Neste sentido, todos colaboram para que os resultados sejam os melhores para o todo, pois a sustentabilidade do todo é a sobrevivência das partes. Para contribuir na transição do Mundo dos Custos para o Mundo dos Ganhos são propostos novos processos e indicadores adequados às proposições. Essas são apresentadas na sequência do trabalho.

\subsection{A Proposição do novo processo de precificação}

Uma vez encontrada uma proposição para o conflito estabelecido no Diagrama de Evaporação das Nuvens, o próximo passo no Processo de Raciocínio da Teoria das Restrições seria a construção da Árvore da Realidade Futura, consolidando, dessa maneira, a etapa de "Para o que mudar?" Procurando ser conciso no presente artigo, será apresentado apenas o resultado dessa Árvore, ou seja, a proposta de redesenho do processo analisado.

\subsubsection{Processo de precificação proposto}

A proposta de redesenho do subprocesso de precificação orientou-se pelo objetivo garantir a sustentabilidade do todo Universitário. Assim iniciou-se o processo pelo levantamento minucioso das questões mercadológicas e de posicionamento do novo produto. A partir desse estudo realizou-se uma análise da capacidade instalada e das oportunidades de redução da ociosidade. A ociosidade nas IESs é um ponto relevante, uma vez que se observa, em geral, haver ocupação demasiada em alguns turnos e reduzida em outros.

Definidos turnos e locais para desenvolvimento do produto universitário, devem ocorrer reuniões entre a Unidade Acadêmica de Pró-Educação, a Unidade de Apoio de Marketing e o proponente do novo produto. Essas reuniões devem ter por objetivo a determinação do preço-meta e a previsão da demanda pelo produto. A Figura 6 apresenta esquematicamente o novo processo de precificação.

A partir dessas determinações mercadológicas e de estratégia de ocupação da IES, deve-se identificar e calcular os custos variáveis diretamente afetos ao produto proposto. A seguir, valendo-se dos sistemas de informação, deve-se avaliar o nível de evasão e inadimplência da IES e inserir margens de segurança para o produto universitário, obtendo uma proteção mínima para a estruturação do novo produto.

Tendo por base essas informações, deve-se avaliar o ganho por curso (produto universitário) ou pelo conjunto de módulos (exemplo: há disciplinas que proporcionam "ganho negativo", entretanto, há outras que proporcionam "ganho positivo"), verificando-se assim a sustentação do curso como um todo e não a sustentabilidade das partes

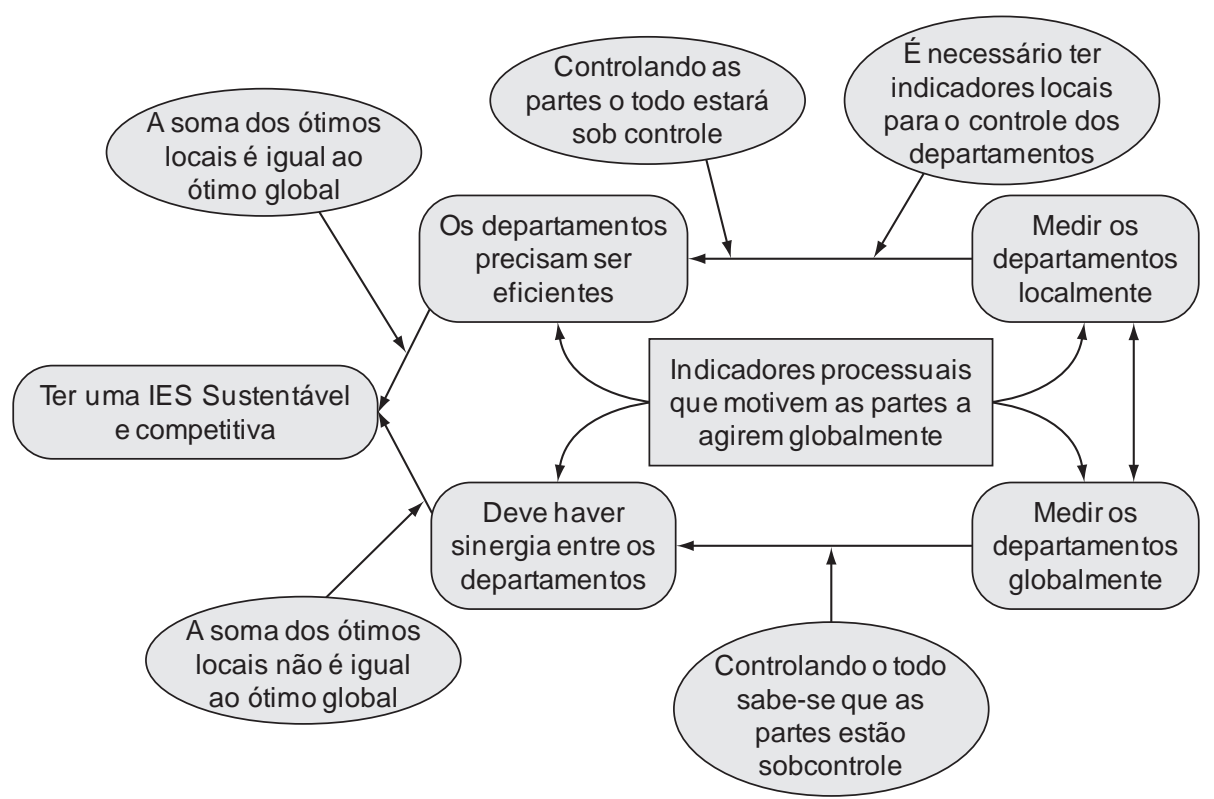

Figura 5. Diagrama de Evaporação das Nuvens - Causa básica da Árvore da Realidade Atual. Fonte: os autores. 


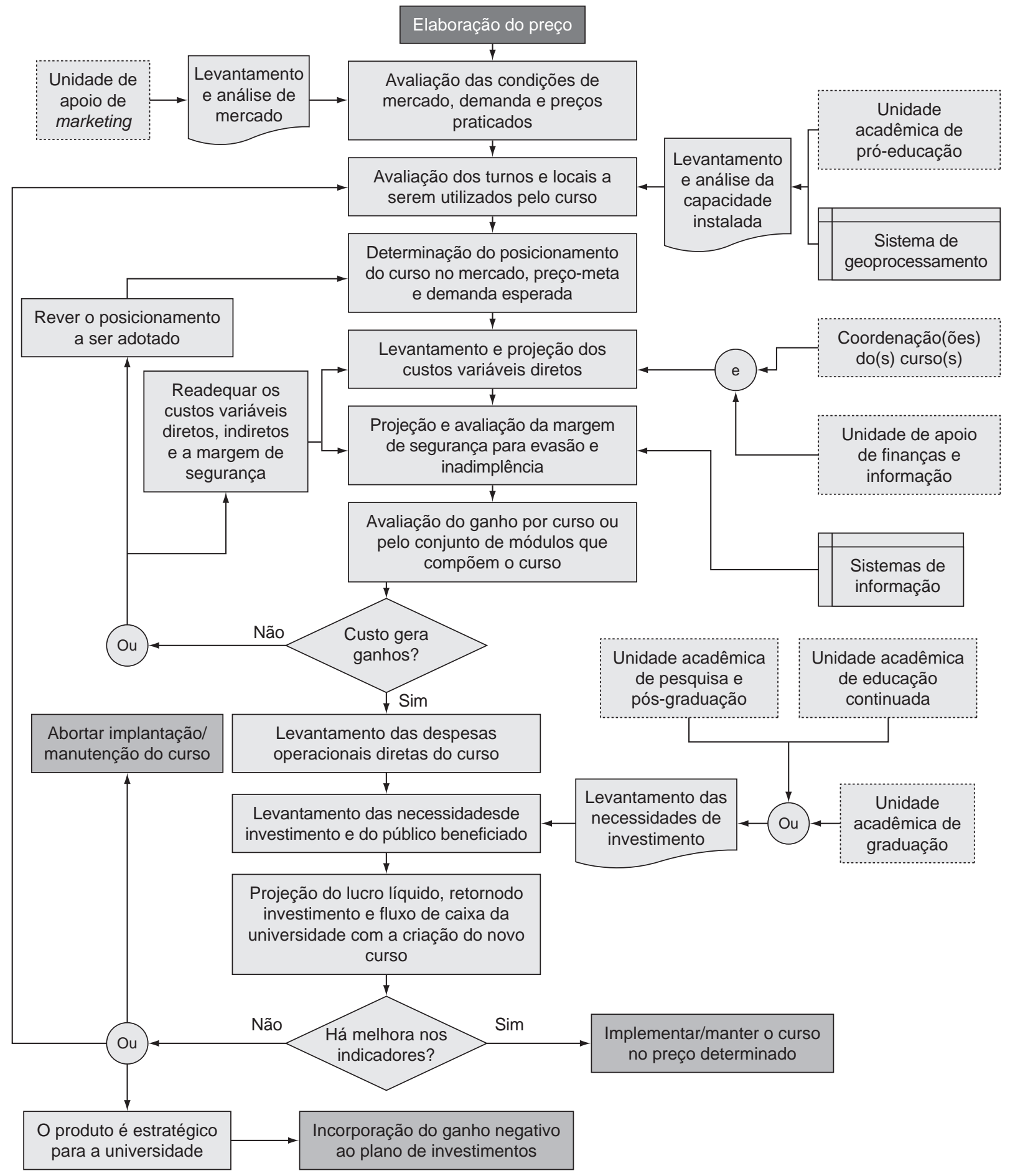

Figura 6. Novo processo de precificação proposto. Fonte: os autores.

individualmente. Não ocorrendo ganho, deve-se rever o posicionamento adotado e, portanto, revisar os cálculos de custo, ou então realizar uma readequação da proteção inserida.

Depois realiza-se o levantamento da Despesa Operacional direta do curso, para que se tenha a informação do impacto da criação na Despesa Operacional da IES. Isso é feito também para que se possa, após o levantamento dos investimentos necessários e do público que o produto atenderá, calcular o impacto do novo curso no Lucro Líquido, no Retorno sobre o Investimento e no Fluxo de Caixa da IES como um todo.

Se o produto não atende os quesitos estabelecidos, restam três alternativas: a) reavaliar o posicionamento em termos 
de turnos e locais a serem utilizados e, consequentemente, realizar todo o reposicionamento de preços e cursos; b) considerar o novo produto universitário como algo estratégico e como uma ação de longo prazo, incorporando dessa forma os ganhos negativos ao Plano de Investimentos da IES; e c) Abortar a implantação/manutenção do curso (produto universitário). Se os quesitos estabelecidos são satisfatoriamente atendidos, lança-se o curso conforme ele foi determinado.

\subsubsection{Indicadores propostos}

Para oferecer alternativas não apenas de processos mas também de indicadores, descrevemos abaixo os indicadores que, em tese, podem proporcionar uma visão mais abrangente objetivando-se um ótimo global para uma organização alinhada ao Mundo dos Ganhos.

a) Ganho do produto universitário: esse indicador tem por objetivo verificar a real contribuição do produto universitário. Apura-se o preço de venda e os custos variáveis diretos do produto e, por consequência, obtém-se o ganho. De modo geral, produtos com "ganhos negativos" não devem ser implementados, embora por questões estratégicas o possam ser debitando-se temporariamente os resultados negativos na conta do Plano de Investimentos.

$$
\begin{aligned}
& \text { Ganho do Produto = Preço de Venda - } \\
& \text { - Custos Variáveis Diretos }
\end{aligned}
$$

Equação 4. Ganho do produto universitário.

b) Lucro líquido da IES: esse indicador revela o impacto do novo produto universitário no resultado da organização como um todo. O objetivo é verificar o lucro líquido total e discutir a participação de cada curso na sustentação da instituição como um todo. Assim, obtém-se o ganho geral por meio do somatório dos ganhos dos produtos acrescido da diferença entre ganho e despesa operacional do produto delta.

$$
\begin{aligned}
& \text { Lucro Líquido Geral }=\left(\sum_{i=1}^{n} \text { Ganho Produto }{ }_{i}+\right. \\
& + \text { Ganho Produto } \Delta)-(\text { Desp. Oper. + Desp. Oper. } \Delta)
\end{aligned}
$$

Equação 5. Lucro líquido geral.

c) Retorno sobre o investimento geral: por meio desse índice verifica-se como o novo produto contribui no retorno sobre os investimentos realizados. Cursos com utilização marginal da capacidade instalada realizados em turnos alternativos em geral melhoram o retorno sobre os investimentos realizados. Esse índice é uma avaliação relativa e complementar ao lucro líquido geral.

$$
\begin{gathered}
\text { Retorno Invest. Geral }= \\
\left(\sum_{\mathrm{i}=1}^{\mathrm{n}} \text { Ganho Produto }_{\mathrm{i}}+\text { Ganho Produto } \Delta\right)-^{(\text {Desp. Oper. Total + Desp. Oper. } \Delta)} \\
\frac{\text { Investimento Total + Investimento } \Delta}{}
\end{gathered}
$$

Equação 6. Retorno sobre o investimento geral.

d) Fluxo de caixa da IES: esta medida procura demonstrar o impacto do novo produto na condição necessária para a sobrevivência da IES. Assim, apura-se o resultado do período "i" até " $n$ " e a previsão de faturamento e desembolso do período "i" e do produto universitário "k".

$$
\begin{aligned}
& \text { Fluxo de Caixa Geral }=\sum_{i=1}^{n} \text { Resultado }_{i}+ \\
& +\sum_{i=1}^{n} \sum_{k=1}^{n} \text { Faturamento }_{i k}-\sum_{i=1}^{n} \sum_{k=1}^{n} \text { Desembolsos }_{i k}
\end{aligned}
$$

Equação 7. Impacto do novo produto no fluxo de caixa geral.

\section{Conclusões}

Apesar das insistentes críticas teóricas à utilização do paradigma do Mundo dos Custos nos sistemas gerenciais de custeio, pesquisas empíricas (GUERREIRO, 2003) comprovam a predominância dessa abordagem em relação à do Mundo dos Ganhos.

O desenvolvimento do diagnóstico sistêmico dos processos da área econômico-financeira, através da Árvore da Realidade Atual, constata a existência de um número reduzido de causas básicas responsáveis por diversos efeitos indesejáveis na organização estudada. A gestão pelos ótimos locais, motivando as partes (unidades, departamentos, programas etc.) a buscarem a sua maximização individual traz como consequência indesejada uma série de ações locais que prejudicam a desempenho global da organização.

Entretanto, afora as críticas teóricas realizadas ao Mundo dos Custos e as constatações empíricas de suas consequências, as organizações encontram-se estagnadas nesse paradigma. A proposição apresentada nessa pesquisa é que esta situação sustenta-se no desenho dos processos atuais e de seus indicadores.

Esse trabalho apresenta algumas limitações: inicialmente, os processos propostos não foram implementados e, portanto, não foi possível aferir sua exiquibilidade empiricamente. Outra limitação associa-se ao poder de generalização da pesquisa. Nesse sentido, a mesma pode ser generalizável teoricamente mas não em termos populacionais. Outra limitação do trabalho está no número de processos redesenhados. Assim, outros processos gerais poderiam ser redesenhados, em particular os econômico-financeiros. Por fim, outra limitação está na natureza da instituição analisada - podem haver 
semelhanças e discrepâncias em relação a empresas de outros setores.

Por um lado, essas limitações se configuram como aspectos que devem ser considerados para a correta leitura desse trabalho. Por outro, podem ser consideradas objetos de pesquisa, desafios para que outros tragam colaborações para esse campo de pesquisa. Dessa maneira sugere-se, inicialmente, a replicação desse estudo em outras realidades, para a verificação dos resultados e da abordagem proposta. Também seriam relevantes estudos que comparassem, ao longo do tempo, decisões baseadas no Mundo dos Custos em relação a decisões no Mundo dos Ganhos. Ainda, seriam bem vindos estudos que avaliassem o alinhamento dos indicadores utilizados nas organizações com os preceitos propostos pela Teoria das Restrições. Além disso, mais estudos que busquem efetivamente evitar o comportamento insular nas organizações são necessários.

Esse trabalho procurou contribuir na construção de um elo entre essas duas abordagens por meio da proposição de um conjunto de processos alinhados ao novo paradigma. Dando sustentabilidade a esses processos, definiu-se um grupo de indicadores globais com uma abordagem sistêmica e processual. Essa abordagem, aqui ilustrada no subprocesso de precificação proposto, foi utilizada para uma gama de subprocessos da área econômico-financeira da IES, construindo-se elos, em termos de processos, com o Mundo dos Ganhos. A continuidade dessa pesquisa buscará a implementação desses subprocessos, bem como a publicação dos resultados obtidos.

\title{
Process analisys for higher education institutions: from the cost world to the throughput world
}

\begin{abstract}
This paper investigates a University's pricing process, comparing two different accounting approaches: traditional cost accounting and Theory of Constraints. Relying on concepts from the Theory of Constraints, this paper applies the principles of the Thinking Process and Throughput Accounting to review the current approach to this process. As a result, the paper evaluates the dynamics behind such processes and, based on throughput accounting, presents a new approach in tackling this.
\end{abstract}

Keywords: Throughput accounting. Costs accounting. Theory of constraints. Business process engineering.

\section{Referências bibliográficas}

ALVAREZ, R. R. Análise comparativa de metodologias para análise, identificação e solução de problemas. Porto Alegre, 1995. Dissertação (Mestrado em Engenharia da Produção) Universidade Federal do Rio Grande do Sul.

ANTUNES Jr., J. A. V. et al. Critical issues about the theory of constraints thinking process: A theoretical and practical approach. In: PRODUCTION AND OPERATION MANAGEMENT SOCIETY - POMS, 15, 2004, Cancun. Conference...

BORNIA, A. C. Análise gerencial de custos: aplicação em empresas modernas. Porto Alegre: Bookman, 2002.

BRYMAN, A. Quantity and quality in social research. London: Unwin Hyman, 1988.

CORBETT, T. Contabilidade de Ganhos: a nova contabilidade gerencial de acordo com a Teoria das Restrições. São Paulo: Nobel, 1997.

COX, J.; SPENCER, M. S. Manual da Teoria das Restrições. Porto Alegre: Bookman, 2002.

CSILLAG, J. M. O significado do mundo dos ganhos. Revista de Administração de Empresas, v. 31, n. 2, p. 61-68, 1991.

DAVENPORT, T. H. Reengenharia de processos. Rio de Janeiro: Campus, 1994.
DRAMAN, R. H.; LOCKAMY III, A.; COX III, J. F. Constraintbased accounting and its impact on organizational performance: a simulation of four common business strategies. Integrated Manufacturing Systems, v. 13, n. 4, p. 190-200, 2002.

DUGDALE, D.; JONES, C. Accounting for throughput: techniques for performance measurement decisions and control. Management Accounting, v. 74, n. 11, p. 52-56, 1997.

EINSENHARDT, K. M. Building theories from case study research. Academy of Management Review, v. 14, p. 532-550, 1989.

ELLRAM, L. M. The use of the case study method in logistics research. Journal of Business Logistics, v. 17, n. 2, p. 93-138, 1996.

GIL, A. C. Métodos e técnicas de pesquisa social. São Paulo: Atlas, 2007.

GOLDRATT, E. M. A Síndrome do palheiro: Garimpando informações num oceano de dados. São Paulo: C. Fulmann, 1991.

GOLDRATT, E. M. A corrida pela vantagem competitiva. São Paulo: C. Fulmann, 1992.

GOLDRATT, E. M. What is thnig called theory of constraints and how shoud it be implemented? New York: Noth River Press, 1990. 
GOLDRATT, E. M. Não é sorte: a aplicação do processo de raciocínio da Teoria das Restrições. São Paulo: Nobel, 2004a.

GOLDRATT, E. M. TOC insight sinto finance and measurements. New York: Goldratt's Marketing Group, 2004b.

GUERREIRO, R. A meta da empresa: seu alcance sem mistérios. São Paulo: Atlas, 1996.

GUERREIRO, R. O paradoxo da utilização dos modernos sistemas contábeis gerenciais. In: CONGRESSO BRASILEIRO DE CUSTOS, 10, 2003, Guarapari. Palestra...

GRAVES, C.; GURD, B. Throughput accounting: a revolution in the making? Australian CPA, v. 68, n. 7, p. 36-38, 1998.

HUNT, V. D. Process mapping: how to reengeneer your business processes. New York: John Wiley \& Sons, Inc., 1996.

JOHANSSON, H. J. et al. Processos de negócios. São Paulo: Pioneira, 1995.

KLEIN, D. J.; DEBRUINE, M. A Thinking process for establishing management polices. Review of Business, v. 16, n. 3, p. 31-37, Spring 1995.

MARQUES, J. A. V. C.; CIA, J. N. S. Teoria das restrições e contabilidade gerencial: interligando contabilidade a produção. Revista de Administração de Empresas, v. 38, n. 3, p. 34-46, 1998.

MOTTA, F. G. Fatores condicionantes na adoção de métodos de custeio em pequenas empresas. São Carlos, 2000. Dissertação (Mestrado em Engenharia de Produção) - Universidade de São Paulo - USP.

McMULLEN, T. B. Introduction to the theory of constraints management system. [S.1.]: The St. Lucie Press, 1998. (APICS Series on Constraints Management).
NOREEN, E.; SMITH, D.; MACKEY, J. T. A teoria das restrições e suas implicações na contabilidade gerencial. São Paulo: Educator Editora, 1996.

PIDD, M. Modelagem empresarial: ferramentas para tomada de decisão. Porto Alegre: Bookman, 1998.

PLANTULLO, V. L. Um pouco além do Just-inTime: Uma abordagem à Teoria das Restrições. Revista de Administração de Empresas, v. 34, n. 5, p. 32-39, 1994.

RODRIGUES, L. H. A aplicação do processo de pensamento da teoria das restrições no ensino de conceito básicos de administração das operações. In: ENCONTRO ANUAL DA ASSOCIAÇÃO NACIONAL DE PÓS-GRADUAÇÃO E PESQUISA EM ADMINISTRAÇÃO - ENANPAD, 28, 2004, Curitiba.

RUMMLER, G. A.; BRACHE, A. P. Melhores desempenhos das empresas. São Paulo: Makron Books, 1994.

SCHEINKOPF, L. J. Thinking for a change: Putting TOC thinking process to use. [S.1.]: The St. Lucie Press, 1999. (APICS Series on Constraints Management).

SLACK, N. et al. Administração da produção: edição compacta. São Paulo: Atlas, 1999.

SMITH, D. The Measurement Nigthmare. [S.1.]: The St. Lucie Press, 2000. (APICS Series on Constraints Management).

VILLELLA, C. S. S. Mapeamento de Processos como Ferramenta de Reestruturação e Aprendizado Organizacional. Florianópolis, 2000. Dissertação (Mestrado em Engenharia de Produção) Universidade Federal de Santa Catarina.

YIN, R. K. Estudo de caso: planejamento e métodos. 2 ed. Porto Alegre: Bookman, 2001.

\section{Sobre os autores}

\section{Daniel Pacheco Lacerda}

Programa de Pós-Graduação em Engenharia de Produção e Sistemas - UNISINOS

Av. Unisinos, 950, CEP 93022-000, São Leopoldo, RS, Brasil

e-mail: dlacerda@unisinos.br

\section{Luis Henrique Rodrigues}

Programa de Pós-Graduação em Engenharia de Produção e Sistemas - UNISINOS

Av. Unisinos, 950, CEP 93022-000, São Leopoldo, RS, Brasil

e-mail: Ihr@unisinos.br

\section{Alexandre Costa da Silva}

Programa de Pós-Graduação em Engenharia de Produção e Sistemas - UNISINOS

Av. Unisinos, 950, CEP 93022-000, São Leopoldo, RS, Brasil

e-mail: alexandres@unisinos.br 